\title{
Perancangan Kampung Vertikal Ngagel Baru: Reinterpretasi Pola Sirkulasi pada Kampung
}

\author{
Ahmad Rizal Sholikhuddin dan Arina Hayati \\ Departemen Arsitektur, Fakultas Teknik Sipil dan Perencanaan, Institut Teknologi Sepuluh Nopember (ITS) \\ e-mail: arina_h@arch.its.ac.id
}

\begin{abstract}
Abstrak-Kesenjangan sosial adalah sebuah realita yang sering kita jumpai pada masyarakat di kota-kota besar yang disebabkan oleh perbedaan dalam kualitas hidup yang sangat kontras dan tidak jarang membuat masyarakat enggan berinteraksi. Surabaya adalah kota terbesar kedua di Indonesia dengan indeks nilai gini rasio sebesar 0,42. Sehingga tergolong dengan tingkat ketimpangan yang harus dikendalikan. Menggunakan pendekatan vernakular kontemporer, perancangan kampung vertikal bertujuan untuk menciptakan wujud tampang yang dapat menjadi ruang transisi di antara bangunan high-rise dan perkampungan sekitar. Hasil rancangan merupakan konsep redevelopment perumahan yang mengacu kepada hunian vernakular khas Indonesia yaitu hunian di lingkungan kampung agar penghuni permukiman tidak harus berpindah dari tempat mereka berasal.
\end{abstract}

Kata Kunci-Kampung Vertikal, Kesenjangan, Redevelopment.

\section{PENDAHULUAN}

$\mathrm{P}$ OTRET kesenjangan sosial adalah sebuah realita yang sering kita jumpai pada masyarakat di kota-kota besar yang disebabkan oleh perbedaan dalam hal kualitas hidup yang sangat kontras (Gambar 1 dan Gambar 2). Dalam pembahasan yang lebih mudah, kesenjangan sosial diartikan sebagai ketimpangan atau ketidaksamaan akses untuk mendapatkan atau memanfaatkan sumber daya yang tersedia.

Pada hakikatnya perbedaan antara masyarakat kelas atas dan masyarakat kelas bawah akan tetap ada, dalam sistem sosial ekonomi manapun. Hal yang lebih diperlukan adalah bagaimana memperkecil kesenjangan dan menyamarkan batas tersebut sehingga lebih mendekati perasaan keadilan sosial atau perlakuan adil tanpa diskriminasi [1]. Ketimpangan sosial merupakan buah dari pembangunan yang hanya berfokus pada aspek ekonomi dan melupakan aspek sosial. "(Andrinof A. Chanigo).

Gini ratio atau indeks ketimpangan Provinsi Jawa Timur mencapai 0,42. Sedangkan Kabupaten/Kota dengan urutan tertinggi diperoleh Kota Surabaya dengan indeks nilai yang sama (Tabel 1) [2]. Angka 0,4 hingga 0,6 sudah termasuk kategori lampu kuning. Sehingga tingkat ketimpangan pada Kota Surabaya harus diperhatikan dan dikendalikan. Ketidakmerataan kualitas hidup masyarakat tersebut perlu untuk didegradasi karena kesenjangan dapat mempengaruhi sektor perkembangan ekonomi.

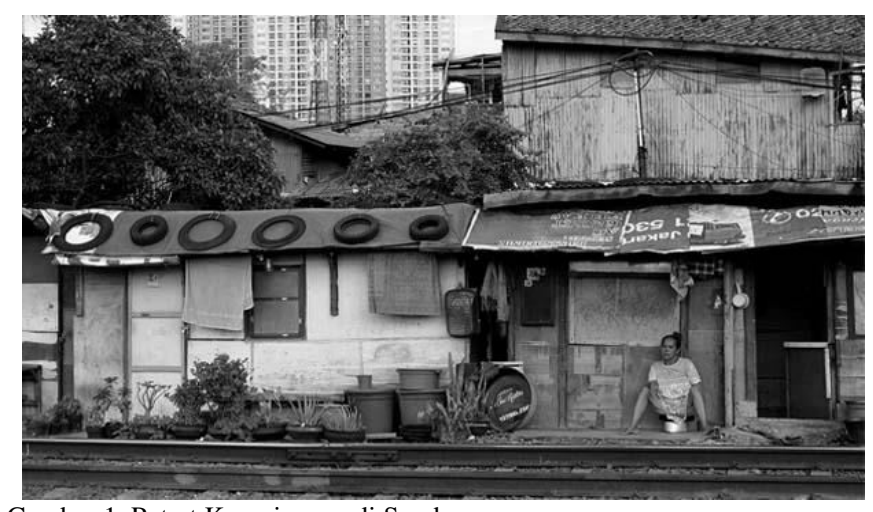

Gambar 1. Potret Kesenjangan di Surabaya.

(Sumber: surabayanews.co.id)

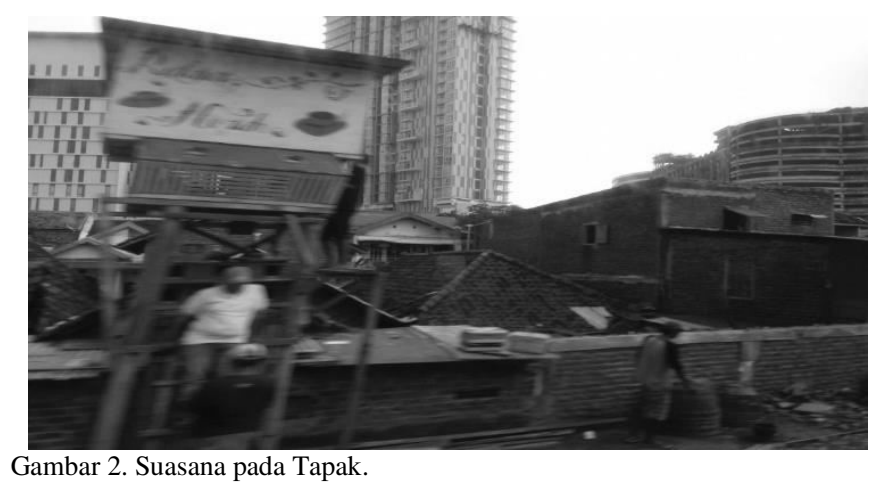

(Sumber: Dokumentasi Pribadi)

Tabel 1.

Gini Ratio Kabupaten/Kota di Provinsi Jawa Timur 2008-2015

\begin{tabular}{|c|c|c|c|c|c|c|c|c|}
\hline Kabupaten/Kota & 2008 & 2009 & 2010 & 2011 & 2012 & 2013 & 2014 & 2015 \\
\hline 01. Pactan & 0.34 & 0.27 & 0.29 & 0.34 & 0.31 & 0.33 & 0.31 & 0.33 \\
\hline 02. Ponorogo & 0.22 & 0.25 & 0.25 & 0.29 & 0.31 & 0.34 & 0.31 & 0.36 \\
\hline 03. Trengzalek & 0.24 & 0.28 & 0.29 & 0.34 & 0.32 & 0.35 & 0.31 & 0.37 \\
\hline 04. Tulungagung & 0.29 & 0.28 & 0.27 & 0.32 & 0.34 & 0.37 & 0.31 & 0.36 \\
\hline 05. Blitar & 0.28 & 0.30 & 0.27 & 0.33 & 0.36 & 0.33 & 0.30 & 0.33 \\
\hline 27. Sampang & 0.25 & 0.27 & 0.24 & 0.26 & 0.25 & 0.25 & 0.23 & 0.30 \\
\hline 28. Pamekasan & 0.25 & 0.24 & 0.26 & 0.28 & 0.24 & 0.25 & 0.26 & 0.34 \\
\hline 29. Summenep & 0.24 & 0.24 & 0.27 & 0.27 & 0.30 & 0.29 & 0.25 & 0.26 \\
\hline 71. Kediri & 0.29 & 0.30 & 0.28 & 0.39 & 0.39 & 0.33 & 0.31 & 0.40 \\
\hline 72. Biltar & 0.32 & 0.32 & 0.33 & 0.34 & 0.38 & 0.40 & 0.35 & 0.37 \\
\hline 73. Malang & 0.35 & 0.34 & 0.35 & 0.36 & 0.48 & 0.38 & 0.37 & 0.38 \\
\hline 74. Probolinggo & 0.36 & 0.24 & 0.24 & 0.33 & 0.28 & 0.38 & 0.33 & 0.36 \\
\hline 75. Pasuruan & 0.29 & 0.28 & 0.27 & 0.37 & 0.37 & 0.32 & 0.31 & 0.39 \\
\hline 76. Kota Mojokerto & 0.28 & 0.33 & 0.31 & 0.36 & 0.30 & 0.30 & 0.31 & 0.36 \\
\hline 77. Kota Madiun & 0.25 & 0.30 & 0.32 & 0.33 & 0.35 & 0.43 & 0.34 & 0.38 \\
\hline 78. Surabaya & 0.32 & 0.36 & 0.36 & 0.37 & 0.40 & 0.37 & 0.39 & 0.42 \\
\hline 79. Batu & 0.27 & 0.25 & 0.31 & 0.32 & 0.32 & 0.31 & 0.29 & 0.36 \\
\hline JAWA TIMUR & 0.35 & 0.32 & 0.31 & 0.36 & 0.36 & 0.36 & 0.37 & 0.42 \\
\hline
\end{tabular}

(Sumber: Badan Pusat Statistik, 2015) 


\section{EKSPLORASI DAN PROSES RANCANG}

Dalam rancangan menginterpretasikan aktivitas sosial budaya yang berlangsung di dalam kampung, salah satu yang paling menarik terjadi di dalam sirkulasi kampung itu sendiri yaitu pada sebuah gang kampung. Langkah yang dilakukan yaitu survei pemetaan perilaku meliputi suatu lokasi atau area yang menunjukan aktivitas manusia, dan pengamatan perilaku pengguna terhadap ruang atau bangunan (Gambar 3).

Langkah-langkah tersebut kemudian akan membantu objek rancangan dalam mencapai tujuan sehingga tidak terlepas dengan kebutuhan yang telah ditentukan (Gambar 4) [3]. Pola kegiatan sosial masyarakat kampung yang horizontal akan tetap dipertahankan dalam hunian yang vertikal yaitu dengan mempertahankan ruang-ruang berkantong pada gang kampung yang digunakan untuk berbagai aktivitas.

Objek rancangan dapat menyamarkan batas kesenjangan dengan menjadikan ruang transisi diantara bangunan high-rise dan perkampungan melalui redevelopment kampung dan menambahkan fungsi lain sebagai wadah pemicu interaksi sosial yang dapat memperkuat hubungan interdependensi antara masyarakat kelas atas dan masyarakat kelas bawah (Gambar 5).

\section{A. Pendekatan Vernakular Kontemporer}

Pendekatan yang digunakan adalah desain vernakular kontemporer yang berfungsi untuk membantu mewujudkan karakteristik rumah pada kampung. Pendekatan ini dipilih karena konteks tapak yang berada tepat berdampingan dengan bangunan tinggi yang modern sehingga rancangan ditujukan untuk dapat mengekspresikan lokalitas dan potensi setempat. Terjadinya bentuk-bentuk atau model vernakular disebabkan oleh enam faktor yang dikenal sebagai modifying factor antara lain, faktor bahan, metode konstruksi, faktor teknologi, faktor iklim, pemilihan lahan dan faktor sosial-budaya [4].

\section{B. Prinsip Reinterpreting Tradition}

Dalam objek rancangan menerapkan prinsip dari reinterpreting tradition yang menurut Lim, William S.W/Tan, Hock Beng, (1998) memiliki pengertian yaitu menginterpretasi ulang terhadap nilai-nilai yang terdapat dalam arsitektur vernacular. Proses merancang dilakukan dengan mengkonfigurasi ulang elemen-elemen ruang pada arsitektur vernakular, dengan konsep keseimbangan yang lebih modern, yang mana bentuk tradisional formal tidak dibuang melainkan ditransformasikan melalui jalan penyegaran kembali. Hasilnya dapat berupa defamiliarisasi, yaitu pengasingan bentuk dimana dia ada namun tidak nampak ada.

- Interpretasi Budaya

Menghadirkan karakteristik sebuah kampung ke dalam hunian vertikal sehingga masyarakat yang tinggal tetap merasakan suasana kampung. Penataan zona menginterpretasikan pola susunan pada rumah Jawa yang kemudian disesuaikan dengan kebutuhan dan tapak (Gambar 6).

- Kombinasi Material

Perpaduan material lokal (batu bata, batu alam) dengan baja dan material transparan menciptakan gradasi pada keseluruhan bangunan.
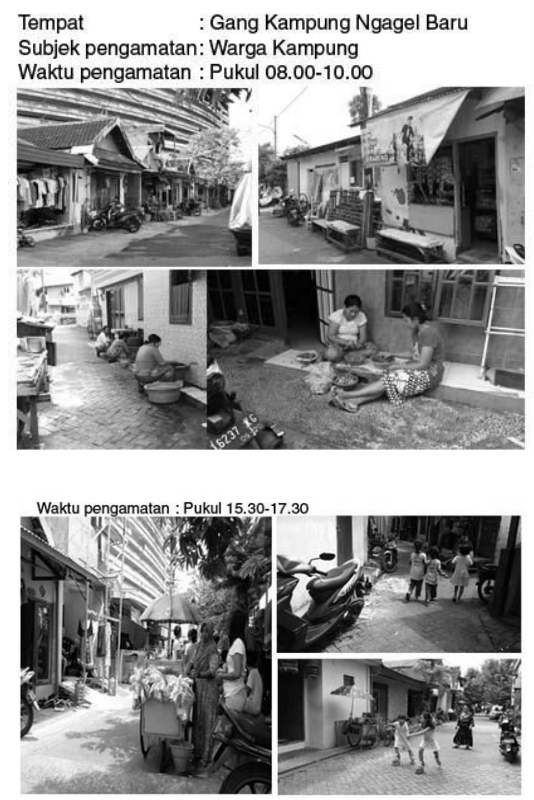

Gambar 3. Hasil Pengamatan Aktivitas.

(Sumber: Dokumentasi Pribadi)

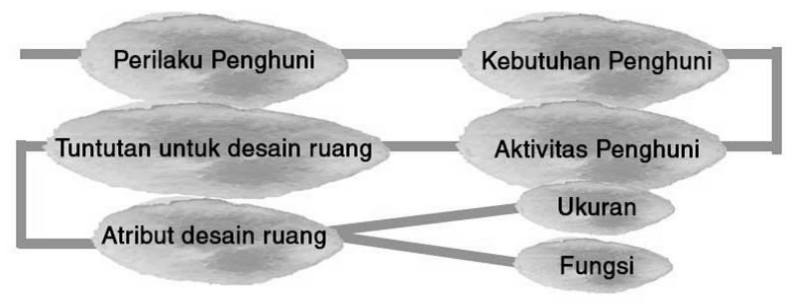

Gambar 4. Langkah Penentuan Kebutuhan Ruang.

(Sumber: Dokumentasi Pribadi)

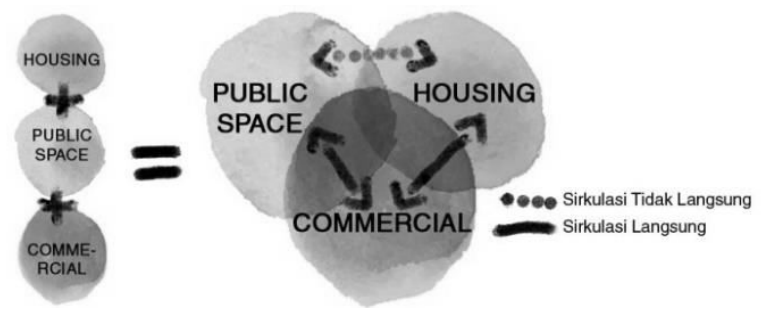

Gambar 5. Ilustrasi Respon Arsitektural.

(Sumber: Dokumentasi Pribadi)

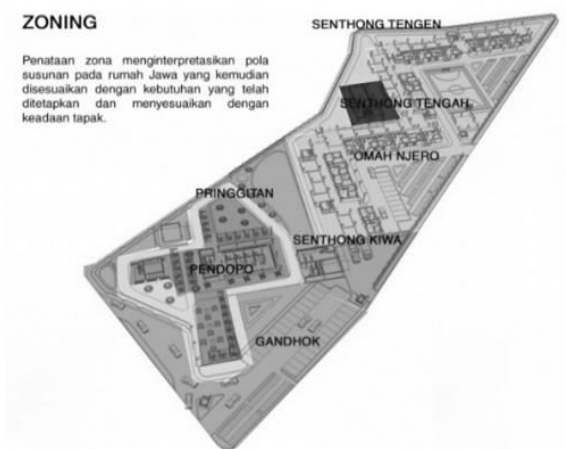

Gambar 6. Reinterpretasi Konfigurasi Ruang.

(Sumber: Dokumentasi Pribadi) 


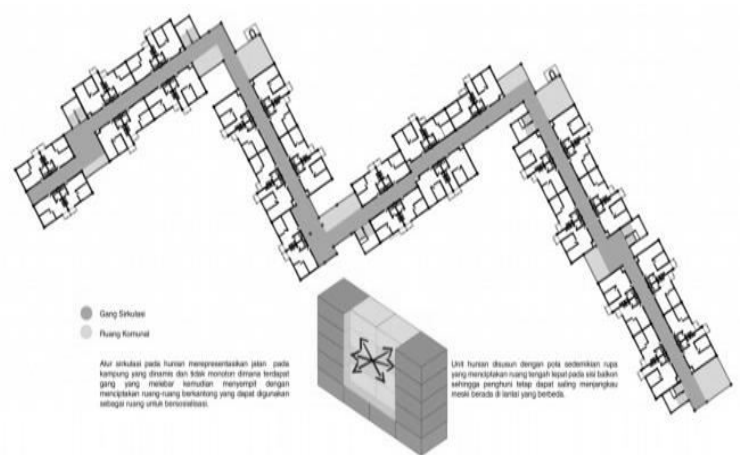

Gambar 7. Konsep Sirkulasi pada Hunian.

(Sumber: Dokumentasi Pribadi)
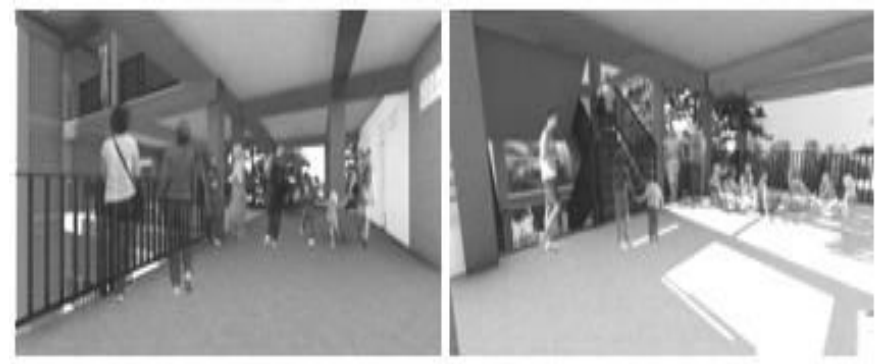

Gambar 8. Ruang Komunal.

(Sumber: Dokumentasi Pribadi)

\section{HASIL RANCANGAN}

Objek rancang merupakan sebuah kampung dengan fasilitas penunjang yang dirancang aksesibel bagi segala kalangan yang bertujuan untuk menginisiasi interaksi sosial.

Beberapa fungsi yang diwadahi adalah sebagai berikut:

1. Redevelopment perkampungan dengan penataan ruang untuk unit-unit hunian warga yang lebih humanis.

2. Area komersial berupa sentra kuliner untuk mengakomodasi kebutuhan dalam kegiatan ekonomi informal (Gambar 13).

3. Ruang publik berupa ruang terbuka hijau dengan fasilitas taman bermain dan olahraga sebagai wadah untuk menginisiasi interaksi sosial (Gambar 12).

\section{A. Sirkulasi}

Alur sirkulasi pada hunian merepresentasikan jalan pada kampung yang dinamis dan tidak monoton dimana terdapat gang yang melebar kemudian menyempit dengan menciptakan ruang-ruang berkantong yang dapat digunakan sebagai ruang untuk bersosialisasi (Gambar 7).

Konsep koridor dibuat lebih lebar dari hunian vertikal pada umumnya, hal ini menyesuaikan perilaku dari penghuninya yang cenderung bersosialisasi di area sirkulasi. Rancangan mempertahankan gang-gang yang berkantong seperti pada kampung sebagai area komunal (Gambar 8)

\section{B. Posibilitas Interkoneksi}

Rumah kampung pada umumnya di kota Surabaya, terdapat badukan di depan rumah yang difungsikan sebagai pembatas sekaligus tempat duduk untuk bersantai. Elemen arsitektural

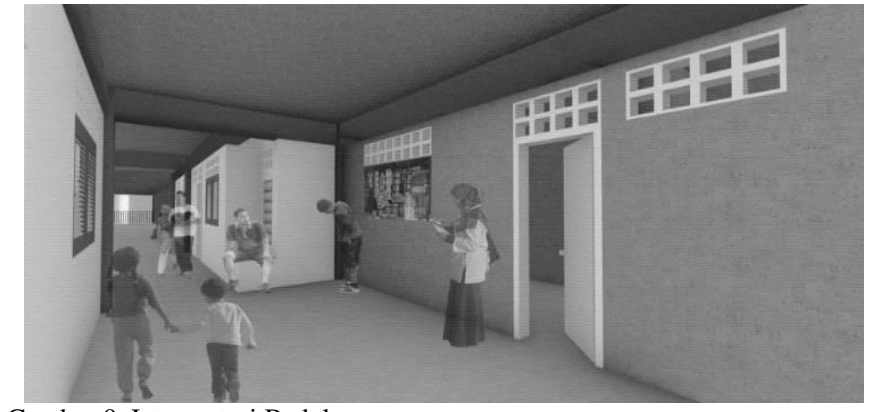

Gambar 9. Interpretasi Badukan.

(Sumber: Dokumentasi Pribadi)

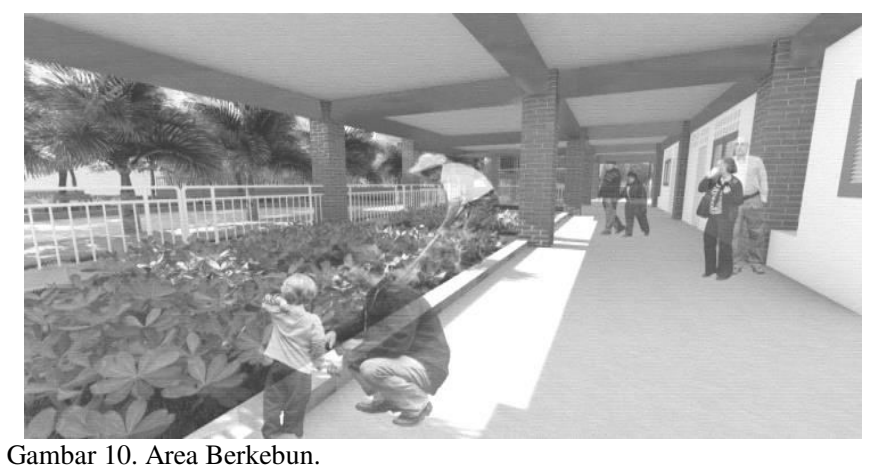

(Sumber: Dokumentasi Pribadi)

ini dihadirkan kembali dengan interpretasi bentuk yang berbeda (Gambar 9).

Kebiasaan masyarakat di kampung yang masih memiliki sedikit area untuk berkebun juga dihadirkan agar penghuni tetap dapat berkebun selayaknya tinggal pada hunian horizontal. Bagi penghuni hal ini sekaligus dapat menarik minat mereka untuk keluar dan bersosialisasi (Gambar 10).

Unit hunian disusun dengan pola sedemikian rupa yang menciptakan ruang tengah tepat pada sisi balkon sehingga penghuni tetap dapat saling menjangkau meski berada di lantai yang berbeda (Gambar 11).

\section{Ruang Luar}

Terdapat plaza yang merupakan bagian dari ketiga irisan fungsi dimana berfungsi sebagai pusat interaksi masyarakat (Gambar 12). Karena mudah diakses dan digunakan oleh siapa saja, maka plaza menjadi titik pertemuan masyarakat yang menyebabkan terjadinya interaksi didalamnya. Selain itu stan bazar diletakkan menyebar pada area sebagai upaya untuk menarik minat pengunjung.

Area komersial berupa sentra kuliner diwadahi oleh stan PKL dan pujasera dengan konsep semi terbuka yang bertujuan untuk menyamarkan batas ruang (Gambar 13). Rancangan memiliki konsep yang sama pula dengan konsep koridor hunian, agar masyarakat kampung tidak merasa asing dengan keberadaan transisi ruang yang ada.

Pada area yang berbatasan langsung dengan lingkungan luar dipisahkan dengan taman yang mudah dijangkau dan tidak terdapat batas masif yang menghalangi sehingga pengunjung masih merasa leluasa (Gambar 14). 


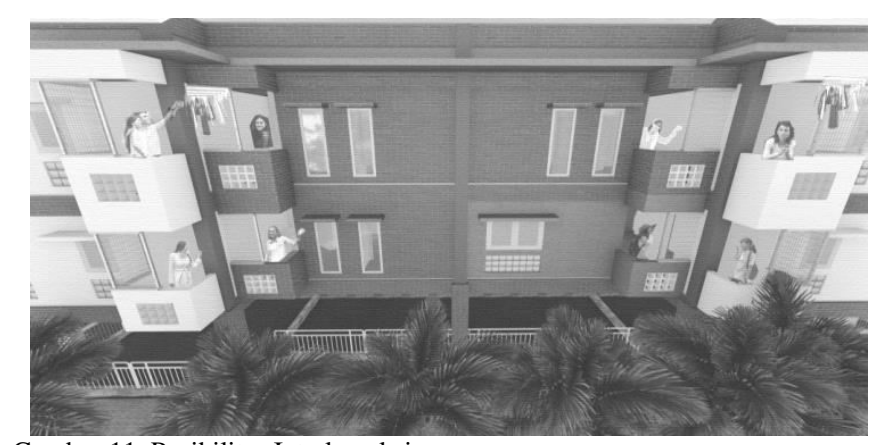

Gambar 11. Posibilitas Interkoneksi.

(Sumber: Dokumentasi Pribadi)

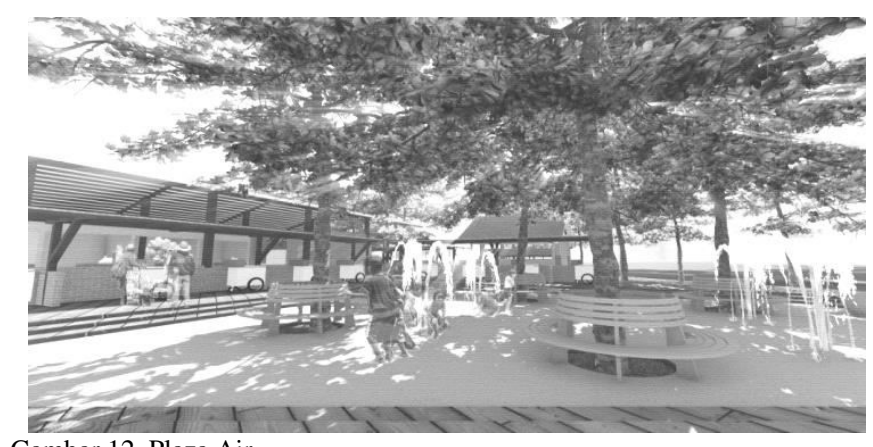

Gambar 12. Plaza Air.

(Sumber: Dokumentasi Pribadi)

\section{KESIMPULAN}

Objek rancangan arsitektur diharapkan dapat menjadi salah satu alternatif dalam penyelesaian kompleksitas isu dan permasalahan kota. Salah satunya adalah bagaimana sebuah rancangan arsitektur dapat meminimalisir batas kesenjangan dengan mewadahi segala kebutuhan dan aktivitas yang pada umumnya dilakukan oleh masyarakat. Untuk itu kebiasaan dan perilaku yang masih dilakukan oleh masyarakat kemudian menjadi budaya dan masih memungkinkan untuk dipadukan, antara lain seperti budaya wisata kuliner dan cangkrukan atau nongkrong. Budaya kehidupan masayarakat di kampung sangat mempengaruhi dalam proses merancang objek arsitektur agar memiliki ekspresi budaya lokal.

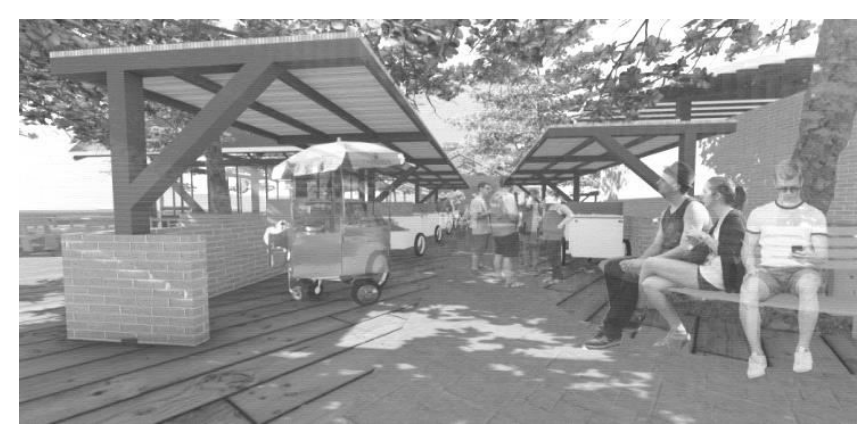

Gambar 13. Sentra PKL.

(Sumber: Dokumentasi Pribadi)

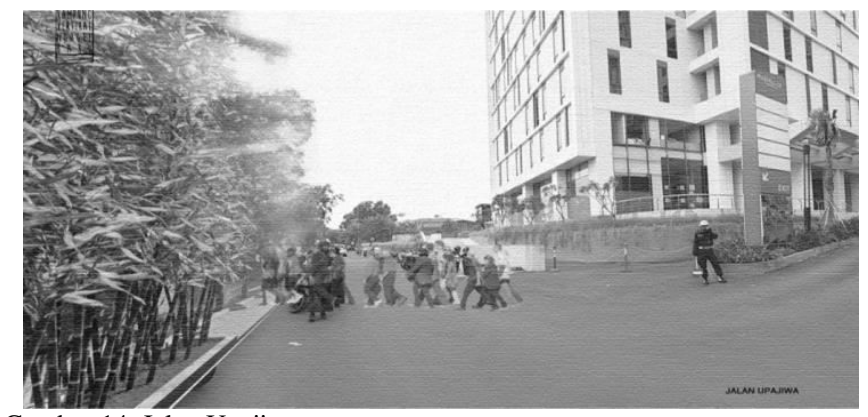

Gambar 14. Jalan Upajiwa.

(Sumber: Dokumentasi Pribadi)

Sehingga, dengan menghadirkan ekspresi budaya pada hasil rancangan kampung vertikal, maka sangat dimungkinkan dapat menarik interdependensi antara kedua subjek. Sehingga sebuah arsitektur jika ingin diterima oleh penggunanya harus dapat mewadahi segala kebutuhan penggunanya dengan berbagai latar belakang sosial, ekonomi, budaya dan lain-lain.

\section{DAFTAR PUSTAKA}

[1] Kompas, "Kesenjangan Sosial di Masyarakat Indonesia," 2016. [Online]. Available: http://www.kompasiana.com/anantatk/kesenjangan-sosialdimasyarakat-indonesia_54f919e6a33311f9028b4794 .

[2] Badan Pusat Statistik Jawa Timur, "No Title," 2015.

[3] R. Sommer and B. Sommer, Behavior Mapping: Practical Guide To Behavior Research. New York: Oxford University Press, 1980.

[4] S. Lim and W.William, Contemporary Vernacular. Singapore: Select Books, 1998. 